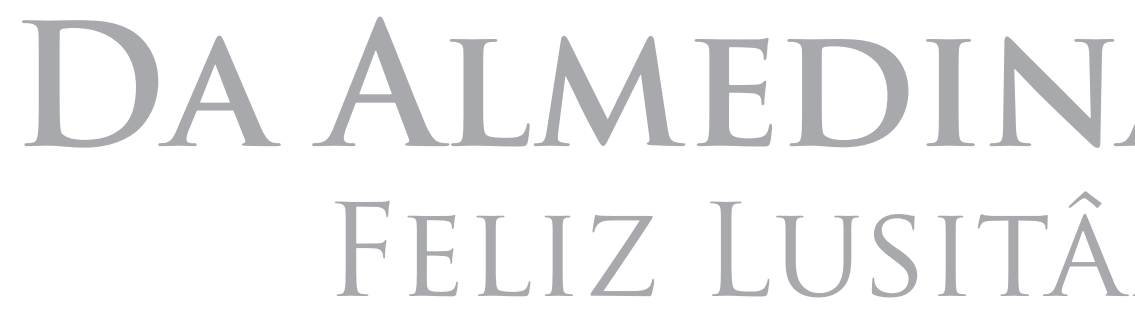

PERSONAGENS PATRIMÔ 


\section{DA ALMEDINA À FELIZ LUSITÂNIA: PERSONAGENS DO PATRIMÔNIO}

\section{CYB E L L E SA L VA D O R M I R A D A}




\title{
DA ALMEDINA À FELIZ LUSITÂNIA: PERSONAGENS DO PATRIMÔNIO
}

\section{Resumo}

A pesquisa analisa comparativamente as formas de apropriação de espaços históricos restaurados em cidades cuja cultura e morfologia possuem semelhanças, devido à sua relação histórica colonial. A realização de pesquisa iconográfica e de entrevistas em Coimbra objetivou traçar um paralelo entre o tratamento de áreas preservadas no bairro inaugural da cidade de Belém do Pará e no Centro Histórico de uma cidade portuguesa. Desta forma, selecionou-se a área intramuros da Almedina (Coimbra) e a região de entorno do Complexo Feliz Lusitânia (Belém) com o objetivo de detectar as percepções da população moradora e dos personagens envolvidos nessas ações. Destacase na análise a repercussão das intervenções no cotidiano dessas áreas.

Palavras-chave: Patrimônio, restauração, centro histórico, percepções das pessoas.

\section{FROM ALMEDINA TO FELIZ LUSITÂNIA: CHARACTERS OF PATRIMONY}

\begin{abstract}
This article compares the forms of appropriation of restored historic places in cities whose cultures and morphologies share similarities, because of their colonial history. Combining iconographic research and interviews, a comparison between the historical downtown in both Coimbra and Belém enabled me to trace a parallel between both cities. I have selected the walled area of Almedida (Coimbra) and the vicinities of Feliz Lusitânia (Belém) in order to investigate the perceptions of the people who lived there and were involved in the restoration processes. I have highlighted the impacts of the remodeling in their daily lives.
\end{abstract}

Keywords: Patrimony, restoration, historical center, people's perceptions.

\section{DE ALMEDINA A LA FELIZ LUSITÂNIA: LOS PERSONAJES DEL PATRIMÓNIO}

\section{Resumen}

La investigación analiza comparativamente las formas de apropiación de espacios históricos restaurados de ciudades cuya cultura y morfología tienen similitudes, por su relación colonial histórico. La realización de la investigación iconográfica y entrevistas en Coimbra objetivó trazar un paralelo entre el tratamiento de áreas preservadas en la ciudad inaugural del distrito de 
Belém do Pará y el Centro Histórico de una ciudad portuguesa. Por lo tanto, hemos seleccionado la zona de intramuros Almedina (Coimbra) y la región que rodea el complejo Feliz Lusitania (Belém) con el fin de detectar las percepciones de la población residente y los personajes involucrados en estas acciones. Se destaca en el análisis el impacto de las intervenciones en estas áreas cotidianamente.

Palabras-clave: Patrimonio, restauración, centro histórico, percepciones de la población. 


\begin{abstract}
"Reclinada molemente na sua verdejante colina, como odalisca em seus aposentos, está a sábia Coimbra, a Lusa Atenas. Beija-lhe os pés, segredando-lhe de amor, o saudoso Mondego. (...) vê-de-la branquejando, coroado do edifício imponente da Universidade, asilo da sabedoria." "O Primo Basílio", Eça de Queiroz (2000: 328-329)
\end{abstract}

\section{SOBRE O MÉTODO}

A cultura é um contexto dentro do qual os acontecimentos sociais podem ser descritos de forma inteligível, isto é, descritos com densidade. A descrição etnográfica é interpretativa, fruto de um discurso social, que tenta salvar o "dito" num tal discurso da sua possibilidade de extinguir-se e descreve um universo de forma microscópica. A partir de um locus definido, pode o antropólogo estudar seu objeto preferencial: as relações sociais. Assim, neste trabalho, os espaços delineados pelo Complexo Feliz Lusitânia e pelo Quarteirão Almedina são o palco para a manifestação de idéias e conceitos dos atores que circulam neles. Os atores tornam-se personagens a medida que o patrimônio é entendido e recriado como cenário. Assim, se na Feliz Lusitânia tudo é belo e iluminado, os atores sobem ao palco histórico como personagens, bem no sentido dos tipos ideais weberianos (Figura 1). Os comerciantes interpretam e saúdam as mudanças esquecendo do restante do bairro abandonado, pois no espaço 'restaurado" podem circular com tranqüilidade, freqüentando o "Boteco das 11", substituto do antigo restaurante, local de sociabilidade das antigas elites. Do mesmo modo os novos moradores vêem-se contemplados nessa dinâmica, atraídos pela

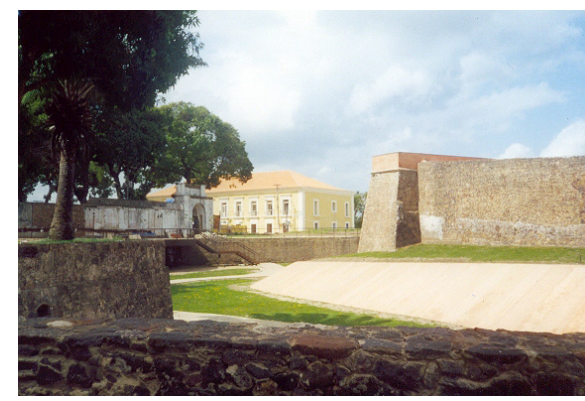

Figura 1. Feliz Lusitânia. Foto de Ronaldo Marques de Carvalho, 2002.

"aura" estetizada do bairro da Cidade Velha (Benjamin 1985). Na Almedina, as pessoas são personagens de um cenário que não é monumental, mas formado pela aparência medieval das edificações e do traçado urbano, onde aqui e ali surgem marcas da muralha, com limites claramente definidos pelo Arco de Almedina (Figura 2). No caminho entre a baixa e a Universidade, Almedina é moradia de estudantes e de idosos, é percurso turístico, é referência histórica, é candidata a Patrimônio Mundial.

O lugar antropológico é o meio onde se exprime a identidade do grupo, e se define de acordo com a flutuação de fronteiras ocorrida na história do grupo. Diz Augè:

$$
\begin{aligned}
& \text { "reservamos o termo lugar antropológico' } \\
& \text { àquela construção concreta e sim- } \\
& \text { bólica do espaço que não poderia } \\
& \text { dar conta, somente por ela, das } \\
& \text { vicissitudes e contradições da vida } \\
& \text { social, mas à qual se referem todos } \\
& \text { aqueles a quem ela se designa um } \\
& \text { lugar, por mais humilde e modesto } \\
& \text { que seja" (Augè 2001:51). }
\end{aligned}
$$

O lugar antropológico é identitário, relacional e histórico, no sentido da vida, situado portanto no extremo oposto dos "lugares de memória”, pois nesses os antigos moradores são "turistas do íntimo". Buscamos 


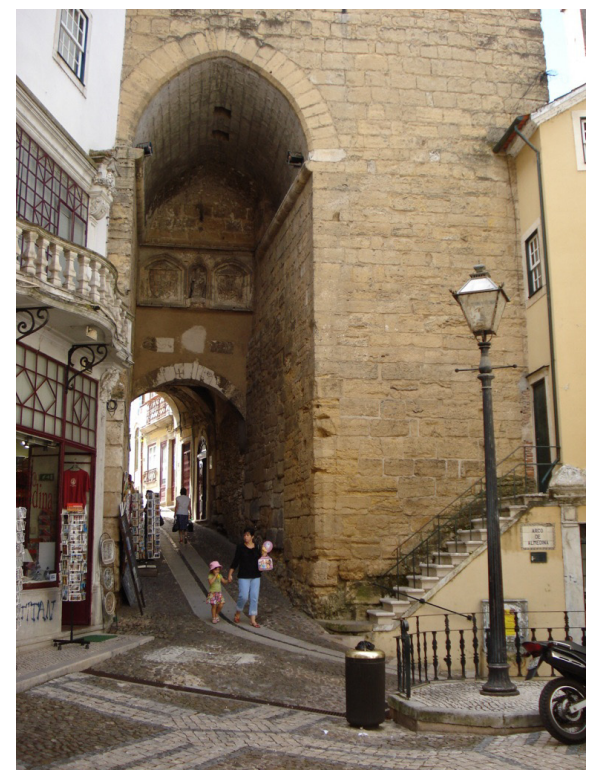

Figura 2. Arco de Almedina. Foto de Ronaldo Marques de Carvalho, 2009.

então entender se a Cidade Velha e a Almedina estão sendo transformados em lugares de memória, em cenários sem alma.

"Os centros urbanos no seu esplendor pós-moderno são algo assim como as imponentes cenografias operísticas em que só a contraluz (à revelia da orientação dos focos de iluminação) deixa ver a urdidura caótica da trama” (Baptista \& Pujadas apud Frias \& Peixoto 2002:20).

Os monumentos são expressões tangíveis da permanência, garantindo a visibilidade da história, contudo, vestidos em roupagens modernas, os edifícios perdem a sua característica de 'autenticidade' (termo tão caro aos estudiosos do patrimônio), passando a figurar apenas enquanto ruínas de um lugar habitado há tempos e que só possui valor evocativo do passado. Após a 'revitalização', a Igreja de Santo Alexandre perdeu sua função de culto religioso, passando a ambiente do culto artístico onde a porta principal per- manece fechada, privando o ambiente de luz natural. Dentro dela, sentimos devaneios de tempos de outrora, enquanto admiramos os púlpitos entalhados em contraste flagrante com as poltronas estofadas.

No intuito de captar as diversas visões que possuem sobre a temática da preservação do patrimônio em Belém, realizou-se documentação fotográfica e entrevistas com os usuários do Complexo Feliz Lusitânia ${ }^{2}$ seguindo o método etnográfico, bem como foi realizada coleta de depoimentos dos moradores da Cidade Velha e com técnicos dos órgãos de preservação. A pesquisa de campo foi realizada entre os anos de 2003 e 2005, tendo como objetivo a elaboração de Tese de Doutorado.

Em Coimbra, a pesquisa tomou o método qualitativo, com observações registradas em forma de Diário de Campo, acompanhado de percurso fotográfico e de entrevistas estruturadas e livres, conforme a oportunidade. Desenvolveu-se durante o mês de julho de 2009, sendo uma aproximação breve com o objeto de estudo. A área eleita foi o Quarteirão Almedina, compreendido pelos limites: Arco de Almedina, Pátio do Castilho, Rua Fernandes Tomás, Beco das Cruzes, Rua das Esteirinhas, Rua Joaquim Antonio de Aguiar, Beco da Carqueja, Rua do Quebra-Costas, Beco da Imprensa e Rua de Sobre-Ripas. A área de Almedina foi tratada pelo Programa de Recuperação de Áreas Urbanas Degradadas em 1990, 1997 e em 2002, com obras de recuperação de edificações habitacionais e edifícios públicos, inclusão de pavimentos acessíveis nas vias e recuperação de infra-estrutura urbana e com a implantação do Gabinete para o Centro Histórico no Arco de Almedina.

A realização de pesquisa iconográfica e de 
entrevistas em Coimbra objetivou traçar um paralelo entre o tratamento de áreas preservadas no bairro inaugural da cidade de Belém do Pará e no Centro Histórico de uma cidade portuguesa. Desta forma, selecionou-se a área intramuros da Almedina (Coimbra) e a região de entorno do Complexo Feliz Lusitânia (Belém) com o objetivo de detectar as percepções da população moradora e dos personagens envolvidos nessas ações de reabilitação do patrimônio edificado.

\section{OLHARES SOBRE A ALMEDINA}

\section{ALMEDINA COMO CASA}

Hoje Freguesia de Coimbra, a denominação Almedina remonta à tomada pelos mouros, e significa "a cidade", ou seja, a parte intra-muros. Configura-se como parte da Alta, a meio caminho entre a Baixa comercial e Alta Universitária. Caracteriza-se culturalmente pelas festas dos estudantes, dentre elas, a Serenata Monumental, ato que antecede a Queima das Fitas. Há também a Feira Medieval, organizada no Largo da Sé Velha pela Delegação de Coimbra do Inatel, Associação para o Desenvolvimento e Defesa da Alta de Coimbra (ADDAC) e Câmara de Coimbra, tentativa de recriar as tradições da cidade.

Na Rua Visconde da Luz, principal artéria comercial da Baixa, situa-se a entrada da Almedina, com a Porta de Barbacã. Olhando para cima, avista-se a Torre de Almedina, e sinto-me numa cabine do tempo. Mas logo volto ao presente ao olhar as lojas de souvenires que emolduram a porta. À direita, no interior do Arco, abre-se a porta do Gabinete para o Centro Histórico de Coimbra. Descortina-se um panorama de prédios simpáticos de quatro pavimentos e três pavimentos mais sótão, um deles com café instalado no térreo e esplanada. Um aviso anuncia apoio técnico à Reabilitação de imóveis e convida proprietários a candidatarse às reformas. Inicia-se a Rua de Fernandes Thomás, e o primeiro imóvel contém um banner azul com o título "A Alta em alta", o que indica que o proprietário do imóvel aderiu ao Programa PRAUD-OBRAS. Dobro o Beco das Cruzes, seguindo à direta até avistar uma bifurcação, tendo ao centro o prédio onde funciona a Real República Prakystão.

O prédio à direita encontra-se reformado, e sigo pela Rua das esteirinhas, à procura do Beco da Carqueja. Inquiro uma senhora que acaba de sair de casa, no Beco da Amoreira, e ela indica onde se situa o Beco. Durante a descida, pergunto informalmente sobre as obras, e ela conta que a sua casa está sendo reformada, mas ela decidiu não mudar-se, permanecendo na mesma durante as obras por medo de perder o valor baixo da renda que pagam, ela e marido, ambos reformados. Dona Maria Olinda Serra e Silva, de 83 anos, gosta de morar no local, e no momento de nosso encontro, está se dirigindo ao Centro de Convivência Ateneu, para onde vai todas as tardes. Ao ser questionada sobre a possibilidade de me receber em sua casa para uma entrevista, não aceita pois teme que o marido não goste. Sente-se um pouco incomodada com as reformas, diante da insegurança de o proprietário querer aumentar as rendas.

Despede-se de mim no Largo da Sé Velha, onde encontro o Sr. Antonio, morador da Rua de Quebra-costas, cuja casa está 
em obras. O Sr. Antonio Silva, de 83 anos, mora há 53 em uma residência arrendada, atualmente com a esposa: "meus filhos são todos casados, e vivi com a minha sogra. Minha sogra já é falecida." Nascido em Coimbra, na Freguesia de Santa Cruz, ao casar viveu na Rua Direita em duas pensões. "Depois saía da Rua Direita e fui para Montes Claros, eram três divisões. E depois vim para aqui há 53 anos, tem quatro divisões: tem estes dois quartos, esta sala e a cozinha, e a casa de banho. Mas a casa de banho já foi feita por mim."’3

As obras de reforma da casa, da qual ocupa uma das duas frações, começou em novembro passado. Comenta que

"Quando esta casa ali estiver pronta, é do mesmo Senhorio a casa ao lado, eu passo pra lá e depois de arranjado eu volto a passar pra qui. Isto estava muito velho. Este teto fui eu que mandei arranjar, está agora pra deitar abaixo. Aqui a cozinha, o ladrilho também fui eu que mandei arranjar. (Anda pela casa e mostra infiltração no quarto). Vê? Quando chove isto molha tudo. Eu tive que tirar a cama, queixei-me, A Câmara contactou o senhorio e eles decidiram arranjar-me a casa. Este é o meu quarto: minha mulher dorme aqui e eu durmo ali onde dormia a minha sogra, a cama de casal está desarmada, para mudarmos para lá."

Sr. Antonio tem a profissão de alfaiate, e trabalhava no próprio quarto. Queixa-se da miséria e do desemprego em Portugal, e da migração que traz insegurança. Conta com emoção o momento em que os operários iriam demolir a casa onde nasceu, na Rua João Cabreiro, em razão das obras para a passagem do Metro. Pediu que espe- rassem o fotógrafo que contratara para registrar a casa, e mostrou-me com carinho as quatro imagens que restaram.

Ao ser questionado se mudaria da casa, afirmou que "se fosse pra melhor, pois ia. E se fosse uma renda acessível, porque a minha reforma são 360 euros, são sessenta e poucos contos. (...) Eu vim pra cá a pagar 250 escudos, e já era muito dinheiro. A única irmã ainda viva mora no cimo da Rua das Covas, hoje Rua Borges Carneiro.

Durante o dia, "quando me aparece qualquer serviços eu faço um fato novo, enquanto não tiver ordem pra me mudar pra li, faço uns consertos, porque antes tive muito trabalho. Fatos que eu tenho foram todos feitos por mim.” Quando não há serviço, sai para um passeio pelos arredores, toma um café no Bar Sé Velha e lê o jornal.

A Almedina é casa também de estudantes... Na República Prakystão converso com Nuno, Catarina, Ana e Tota, ${ }^{4}$ estudantes da UC que, apesar de algumas divergências, em geral tem uma visão crítica em relação às obras, como afirma Catarina:

É curioso, porque nós vivemos numa casa que está a precisar de ser reabilitada, e temos noção de que, apesar de estar a fazer algumas coisas, não sei com os melhores objetivos, não sei até que ponto é a questão de querer candidatar-se a Patrimônio Mundial da UNESCO, a ser uma fonte de turismo, porque esta zona se vai tornando cara, isto é uma zona essencialmente de jovens e de pessoas mais idosas, só que as pessoas mais idosas também devagarinho vão morrendo e isto também vai se renovando e não sei até que ponto não vai se tornar uma zona mais cara, e depois parece-me 
às vezes que são obras de fachada, eu já tive em algumas casas reabilitadas mas dá a impressão que a maior parte da reabilitação é exterior, mas não tenho a certeza disso.

Nas falas dos entrevistados, personagens desse teatro urbano, percebe-se o apego a moradia e a incerteza em relação ao resultado das mudanças que a dimensão "patrimonial" vem agregando ao espaço. As Repúblicas fazem parte da identidade de Coimbra como setor da vida acadêmica cujo valor memorial é reconhecido (Frias \& Peixoto 2002). No interior da Prakistão observam-se desenhos, pinturas, grafites, testemunhos da passagem de estudantes ao longo das décadas, que marcam a história da curta duração, pois a despeito de o imóvel ter uma história de séculos, a micro história contada pelos grafismos também merece atenção durante as reformas.

\section{ALMEDINA COMO PONTO TURÍSTICO}

Segundo Frias \& Peixoto (2002), em Coimbra a dimensão plástica da patrimonialização não tem sido destacada, apenas aspectos da sua economia simbólica. Destaca-se na Almedina o eixo pedonal que se inicia no Arco de Almedina e, percorrendo a Rua de Quebra-costas, termina no Largo da Sé Velha. Vejamos o que narram a respeito:

"Quem percorre este eixo (ponto de passagem obrigatório para qualquer turista) depara-se, debaixo do Arco de Almedina, com uma loja de alfarrabista, como que a simbolizar a vetustez da cidade. O patrimônio sonoro de Coimbra faz-se ouvir através de uma música de fundo, audível a quem passa na rua, que reproduz incessantemente fados de Coimbra.
Dentro da loja (e em expositores colocados na rua), para lá de exemplares antigos de livros, alguns deles ligados à vida acadêmica coimbrã, encontram-se à venda, sob a forma de postais e de azulejos, as marcas mais estereotipadas do país e da cidade (...). Subindo para a Sé Velha, na Rua de Quebra Costas, encontramos um número crescente de lojas de artesanato. A sua instalação é relativamente recente, tendo ocorrido, na maioria dos casos, nos últimos 10 anos, e os produtos que comercializam restringem-se quase exclusivamente às cerâmicas "tradicionais" de Coimbra" (Frias \& Peixoto 2002:22-23).

Durante a caminhada do dia seis de julho, retornando ao Largo da Sé Velha, adentro no Cabido Bar e avisto a Sr ${ }^{a}$ Rosa Maria, ${ }^{5}$ que concede uma entrevista a duas pesquisadoras da Geografia. Segundo a comerciante, é preciso dar condições de vida melhor às pessoas que habitam a Alta. Habitante da Rua do Cabido há 14 anos, tem o Bar do Cabido desde outubro do ano passado, o qual administra com o filho. Nascida em Coimbra, passou muitos anos fora, mas retornou à cidade "porque Coimbra é uma cidade muito especial e quem passa por aqui adora estar aqui. Não se esquece facilmente Coimbra. Sobretudo quem esteve na Universidade e viveu vida acadêmica. Tenho um amor muito especial à cidade de Coimbra. É difícil não gostar de Coimbra."

Segundo ela, há poucas mudanças na área:

"Dessas poucas coisas, umas pra melhor outras pra pior. Para melhor tem-se aqui um carro pequenino que passa por essas ruas estreitas, que ajuda as pessoas mais velhas a dar-lhe as perninhas que elas já não tem. Para poder deslocar-se. Essa é uma 
das coisas boas. Coisas más por exemplo é que quando as pessoas fazem projetos e planos deveriam vir mais ao terreno estudar, verificar e depois aplicar as medidas. O pantufinhas é muito bom, mas tem o horário que deveria ser mais completo, do meio dia e meia às três horas não existe".

Segundo Rosa, há dificuldade de os proprietários recuperarem os imóveis devido às rendas baratas, muito antigas, e por outro lado os arrendatários não se preocupam em manter o imóvel em boas condições, o que, segundo ela, deveria ser sua responsabilidade.

\section{Como sugestão para o $\mathrm{CH}$,}

“(...) seria às pessoas mais velhas dar-lhes opção de se manterem aqui ou de irem para um sítio mais tranqüilo. E depois trazer pra qui a maior quantidade de gente jovem possível, e dar-lhe movimento. Bons bares, boas esplanadas, bons espetáculos de rua, é claro que isso atrai pessoas, atrai jovens, traz nova vida, afasta porque estas ruas escuras, afasta os roubos, afasta a droga, que hoje é um dos problemas que nós temos".

Neste ponto de vista, a renovação dos moradores seria a forma de dinamizar a área, criando atrações culturais que atraísse turistas. Contudo, o que se vê, apesar da tentativa da Câmara e das associações em divulgar e dinamizar as atrações, como apresentações dos Fados de Coimbra nas escadarias de Quebra-costas, é o movimento tímido dos moradores idosos e dos jovens, que aos finais de semana deixam a cidade para visitar a família.

\section{ALMEDINA COMO CAMINHO PARA A UNIVERSIDADE}

Segundo o histórico da cidade de Coimbra, a sede da Universidade é a base das relações que se estabelecem no Centro antigo, em especial na Almedina, que se configura como zona de transição entre a Alta Universitária e a Baixa comercial. Esta visão é veiculada também nas revistas de turismo, que destacam o Arco de Almedina "que funcionava como a entrada principal do burgo. Ainda hoje o arco é utilizado por muitos estudantes como um atalho para a universidade." (Melo 2009:73)

Segundo a comerciante Celeste Antunes, que trabalha na Rua do Quebra-costas há 20 anos, primeiro com uma tabacaria, depois com loja de roupas pronto a vestir e hoje vende atoalhados e alguns souvenires, os negócios estão piores por causa da crise, que é mundial. "As grandes superfícies tendem a atrofiar os mais pequenos. Tenho uma clientela minha que já fiz, portanto, pra atoalhados, pra coisas, facilito os pagamentos, tenho essa clientela que é minha. E depois tenho os que passam, os turistas, que compram as coisas como você." ${ }^{\prime 6}$

Mora na Rua das Flores no 20, e aluga quartos para meninas universitárias. Acha que hoje os prédios estão mais bonitos, e que mais prédios precisam de melhorias. Quanto aos turistas, o segmento em que atua, embora venda lembranças, não é exclusivamente dedicado a este público, e possui clientes permanentes que "Trabalham nas Universidades, são de mais perto, mais longe, nós já temos clientes já é uma amizade, é quase como uma familia. Já são muitos anos a viver com as mesmas pessoas. Qualquer dia vou-me embora e vai me custar muito, já estou muito habituada com eles." 
A Sra. Alzenda Lopes, de 70 anos, dona do Mercado no no 120 da Rua Joaquim de Aguiar acredita que a saída de alguns cursos da UC para outros locais de Coimbra é responsável pelo declínio no movimento da área. "Tínhamos a Faculdade de Letras, há pouco tempo saiu a Faculdade de Medicina, de Farmácia. Conta que há cerca de 20 anos quando retornou do Brasil, vendia 500 pães de tarde e agora a procura caiu para 50. "Quando eu cheguei aqui era muito freqüentado, nem tem comparação, os estudantes das ilhas, as pessoas antigas que viviam já morreram, e as que ficaram se queixam que aqui é muito barulhento. Chega a noite e as pessoas querem descansar e não descansam. Eu como cá não moro não sei."

Com relação ao futuro da Almedina, é pessimista, pois acredita que as casas ficarão devolutas, sem ter quem as queira habitar. Percebe-se, portanto, que o dinamismo promovido pela presença dos universitários é essencial para que a Almedina permaneça viva e renovada, como bem observam as comerciantes. O contato permanente com os clientes torna-se hábito e até amizade, ao contrário da relação com o turista, marcada pela impessoalidade.

\section{ALMEDINA: ÁREA CRÍTICA OU PATRIMÔNIO MUNDIAL?}

No site da Câmara, a política de Reabilitação é definida: "Mais do que recuperar, importa reabilitar." Percebe-se a ênfase no sentido de devolver as qualidades perdidas nas edificações, em busca da autenticidade (ver Peixoto 2006). Segundo o Dossiê de Candidatura ao PRAUD 2006:

"A Universidade de Coimbra organiza neste momento uma candidatura a património mundial da UNESCO. A envolvente desta zona a candidatar a património foi chamada de Zona Tampão da qual faz parte a Alta e a zona a candidatar a fundos PRAUD. Dessa forma é necessário oferecer garantias a que este espaço seja tratado da melhor forma estando prevista a criação de alguns planos de pormenor e salvaguarda" (Gabinete para o Centro Histórico 2006:8).

À noite do dia 3 de julho, houve na Via Latina espetáculo da cantora Dulce Pontes, em comemoração à premiação internacional recebida pela intervenção no local. $\mathrm{Na}$ fala do reitor da Universidade, destaca-se a indignação do mesmo diante das críticas aos altos custos da restauração, sob o pejorativo apelido de "pedras velhas", acentuando a importância histórica da Universidade e sua candidatura a Patrimônio da Humanidade pela UNESCO.

Em entrevista, a Arquiteta Claudia Ascenso do Gabinete para o Centro Histórico relata o processo de recuperação utilizado no Quarteirão Almedina, como parte do Programa de Recuperação de Áreas Urbanas Degradadas (PRAUD 2002), o qual coordena desde 2006. Inicia o relato:

"A situação que nos deparamos há alguns anos é assim: as casas estão devolutas, algumas estão mesmo a necessitar de obras, condições de habitabilidade, por vezes sem casa de banho e sem alguma espécie de cozinha. Essa é a situação que nós encontramos hoje em dia. Para nós fazermos face a todas essas condições, a Câmara conseguiu estabelecer um programa municipal, que é o PRAUD, Programa de Reabilitação de Áreas Urbanas Degradadas, em que ela contribui com $25 \%$ do valor das obras 
previstas. Outros $25 \%$ é do estado, ficando os restantes $50 \%$ a cargo do proprietário. Ou seja, como é que isso se processa: nós analisamos um quarteirão, que é o chamado Quarteirão Almedina, depois posso falar temos outros tipos de quarteirão mas o mais emblemático e o Quarteirão da Almedina, que se vê mais obras, que foi inicial, nós fizemos uma candidatura e essa candidatura foi aceita"?

Aponta como principal questão o congelamento das rendas, que data de 25 de abril de 1974, o que torna o investimento nas casas de aluguel sem retorno. A Câmara divide com o proprietário das casas algumas tarefas de obra consideradas fundamentais como instalação de casas de banho e cozinhas, e reforma de cobertura, contudo os proprietários são "induzidos" a realizar os demais serviços que se fizerem necessários. Os projetos de reforma baseiam-se na melhoria das condições de habitabilidade das pessoas que vivem no imóvel, segundo a Arquiteta, que envolve as áreas de infra-estrutura, acústica, comportamento térmico, além de pesquisas arqueológicas obrigatórias por tratar-se de área de proteção.

Com relação aos moradores, em princípio parecem temerosos ao ter que se realojar, o que é feito ou pelo proprietário, ou pela Câmara. Algumas obras são feitas por etapas, para manter os inquilinos no imóvel, o que acontece em quase a totalidade dos casos. Assim afirma Cláudia: "Mas a maior parte desses moradores são pessoas que pagam rendas baixíssimas, mas tem uma casa na aldeia. Há pessoas que só se mantém à espera de indenização por parte do proprietário."

Em situações nas quais o proprietário não pode arcar com a contrapartida nas obras, o Programa 'Bem presente para o bem fu- turo" arca com as obras, e dá ao proprietário uma percentagem de custo do terreno com o imóvel como estava. "O proprietário fica sempre com uma fração. O objetivo da Câmara é por esses imóveis a venda por preços muito mais reduzidos, porque aqui a especulação imobiliária é muito grande, porque isso vai ser classificado como Patrimônio Mundial da UNESCO, toda compra, toda venda é tudo especulação."

Percebe-se na fala da Arquiteta semelhança com a da dona do Bar do Cabido, quando aponta a pertinência de "renovar" não só os imóveis, mas também seus habitantes.

\section{PENSARES SOBRE A CIDADE VELHA}

\section{A CIDADE VELHA COMO CASA}

Quanto à população moradora do bairro da Cidade Velha, existem interpretações múltiplas que dependem do sentido que o Feliz Lusitânia adquire em sua visão de mundo. ${ }^{8}$ A Cidade Velha é um bairro residencial muito antigo e permanece como local de moradia para familias que se apegaram a ele. As origens desses moradores é em geral portuguesa e sírio-libanesa, além de contar com emigrantes do interior do estado (Tocantins, 1976).

Falar sobre a Cidade Velha é lembrar outra fase na vida de Maria de Belém e Oneide. Ambas são professoras, formadas pela Escola Normal. A professora Belém é filha do poeta Bruno de Menezes, intelectual paraense, e participa ativamente da vida cultural da cidade, além de ser a guardiã da igreja de São João. D. Oneide é viúva de Joaquim Bastos, comerciante pertencente a uma das familias abastadas do bairro, fun- 
cionária aposentada da Companhia de Correios e Telégrafos.

Sobre o projeto, assim opinou Maria de Belém:

“olha, o projeto Feliz Lusitânia os entendidos dizem que foi uma boa coisa para mostrar ao pessoal da cidade e aos turistas a paisagem da cidade, a paisagem da orla marítima ficou realmente mais devassada né, mais apreciada para o (...) Agora arquitetonicamente não sei lhe falar, mas, nós tínhamos uma amiga, uma família muito amiga que morava lá, a família Barroso e morava naquele pedaço onde hoje tem aqueles esguichos de chafariz. Era ali."

Nesta parte a entrevistada relata as lembranças da famillia Barroso, muito religiosa e que tinha no térreo um Colégio freqüentado pela população do bairro, acrescentando que:

"ali já tinha sido desapropriado a casa para fazer nela aquele estabelecimento de subsistência, ${ }^{9}$ que realmente era um estafermo aquilo ali. Então, o agora desse projeto Feliz Lusitânia o que eu lamento é o desaparecimento do restaurante do Círculo Militar. ${ }^{10}$ Isso eu acho uma pena vou te dizer porque: porque nós nos habituamos a ir lá, então a gente gostava de ver porque a gente comia olhando a paisagem, o que a gente não vê na Estação das Docas ${ }^{11}$ que a gente fica mais retraído, a não ser quem vá pro lado de lá. Mas aqui lá não, no restaurante do Círculo Militar a gente ficava, fazia refeição olhando o barco passar a canoinha passar ... aquilo ajudava até o psíquico da pessoa, a gente ficava mais descontraído."

Porém completa argumentando que

"para fazer o trabalho realmente ele tinha de desaparecer e (...) essa parte da gente ficar se deliciando com nossas comidas e ao mesmo tempo olhando a Baía. Aí essa parte ficou um pouco prejudicada. Mas ficou um bonito trabalho ficou bom acabado. A gente tem de novo aí o pessoal mesmo, a comunidade local, né, aceitou, aprovou e vai muita gente é ...muita procura de pra ir se distrair lá, passeio, né, que lá dentro nunca fui ainda naquele restaurante das 11 janelas eu ainda não fui." ${ }^{12}$

D. Oneide conta das várias propriedades da familia Bastos na Cidade Velha, e relata histórias sobre o Palacete Pinho, descrevendo com detalhes a distribuição dos cômodos da casa, e as memórias da convivência com suas moradoras. Lembra que, à época do Leilão dos objetos do Palacete, não se valorizava antiguidades, que eram chamadas "velharias". Acredita que é tarde demais para preservar a Cidade Velha, pois o bairro já está em ruínas, e o tombamento não impede que os moradores sem recursos mantenham seus imóveis em bom estado. Como membro de uma classe tradicional, seja pelas origens, seja pelo poder econômi$\mathrm{co}$, Oneide sente orgulho em ser testemunho vivo de uma época de requinte no bairro, ao qual ela assistiu o declínio. Hoje, a revitalização do entorno do Forte do Castelo significa para ela um eco distante, já que observou ao longo das décadas a substituição de seus vizinhos por novos moradores de origem ribeirinha, aos quais atribui a desfiguração da aparência das casas, "modernizadas" pelos comerciantes que passaram a dominar setores do bairro. ${ }^{13}$

A casa do Sr. Aprígio e de D Zoraide fica ao lado do prédio da FUMBEL, ${ }^{14}$ em frente à Praça Frei Caetano Brandão. ${ }^{15}$ Nascido em Marabá em 1935, Sr. Aprígio vive em 
Belém desde a infância e D. Zoraide nasceu em Igarapé-miri em 1935 e veio para Belém com 7 anos, e desde então reside nesta casa. Ela me conseguiu fotos antigas que mostram a casa com a fachada antiga, antes da reforma modernizadora feita pelo seu pai por volta de 1946. Aprígio já conheceu o Museu de Arte Sacra, mas não o impressionou muito:

“(...) já passei por aí, já vi coisas e catalogaram, reuniram e eu acho válido mas, não me chama assim atenção. Eu conheço aquilo como a palma da minha mão, sabe como é, e igreja de Santo Alexandre por exemplo, depois dessa reforma, inclusive ar condicionado, poltronas estofadas, entendeu, mas eu era mais aquela antiga, daqueles gavetões que dizem, eu não cheguei a constatar isso, mas dizem que os puxadores dos gavetões dos altares eram de ouro ou banhados a ouro e que depois desapareceram".

O bairro, apesar de manter uma população estável, também vem atraindo novos moradores, interessados no diferencial histórico do local, como o arquiteto José Fernandez, ${ }^{16}$ que ocupa com a mãe, a artista plástica Dina Oliveira, um mini-condomínio formado por uma casa antiga e uma edificação adaptada em terreno que possui duas frentes, contando com piscina, escritório e atelier onde trabalham. A familia de arquitetos optou por restaurar uma casa antiga pelo prazer de morar em casa, num bairro central e que vem se beneficiando, na última década, por intervenções públicas.

Para José, o bairro sofreu uma transformação rápida em função das intervenções operadas pelo poder público em alguns pontos do bairro, como no caso do Com- plexo Feliz Lusitânia. A iniciativa privada vai seguindo o interesse público, de forma que a rua onde mora passou por um processo de intensificação comercial na década de 90. Contudo, em alguns pontos, essa reocupação está se fazendo de maneira diferenciada, ou seja, os empreendimentos comerciais estão tirando partido do Patrimônio Histórico como atrativo, como ocorre no caso de bares e restaurantes, bem como novos moradores estão se deslocando para o bairro em função de sua valorização.

A recuperação da área do Complexo $\mathrm{Fe}-$ liz Lusitânia e a construção do Mangal das Garças são fontes de estímulo para que o bairro atraia novos moradores e atividades comerciais, tirando partido das formas antigas dos imóveis para criar ambientes diferenciados em bares e boates. Contudo, nota-se que o efeito difusor esperado pelas intervenções públicas não se concretizou, de modo que comércios voltados ao fluxo turístico não tem tido vida longa, como no caso do casario contíguo à Igreja de Santo Alexandre, onde a loja de somvenirs, a lanchonete e a sorveteria foram substituídas por repartições culturais do governo do Estado.

\section{SOBREVIVÊNCIA NA CIDADE VELHA}

As dificuldades em manter uma casa antiga, com proporções adaptadas às familias grandes e com muitos empregados para cuidar dos serviços domésticos são fatores que propiciam a saída desses habitantes para casa menores, em geral apartamentos, nos quais podem adaptar-se melhor às condições da "vida moderna". A comerciante Ana Lúcia nasceu na Cidade Velha e é fillha do Sr. João, dono da Casa de Ferragens São João e da Fábrica de Velas São João. ${ }^{17}$ A casa em que 
mora, junto com o marido, as duas filhas e o pai pertenceu ao arquiteto José Sidrim. 'Eu moro na Cidade Velha numa casa de Cidade Velha!", afirmou Ana Lúcia. Morar numa casa desse tipo "é lindo, mas é um elefante branco!(...) já é uma construção que não comporta mais a vida moderna...".

Reclama da infra-estrutura precária no bairro, decorrente do não investimento do poder público em pavimentação das vias, em segurança ou em limpeza, "a não ser nas vésperas do Círio, quando a Prefeitura trabalha para melhorar o visual da passagem da romaria."18 O que Ana observa de melhoria no bairro é

"essa parte aqui do Feliz Lusitânia, que realmente foi uma obra muito boa, muito bonita, acho que pro bairro foi excelente, mudou, deu uma outra 'repaginada' nessa área que tava muito feia, muito abandonada. Agora você vê, as pessoas vêm, são lugares bonitos, eu acho que tem que ser por aí."

Como comerciante, Ana comentou o problema que causou aos comerciantes da área a interrupção no trânsito de ônibus com a queda do bloco central do Palacete Pinho: concorda que o bairro não suporta um fluxo intenso de veículos pesados, mas pensa no fluxo de passageiros dos portos Arapari e Jarumã, que é intenso. Reconhece que os cidadãos têm pouca participação coletiva e não se preocupam com o patrimônio público.

A visão de D. Marilza da Conceição Lima Bastos em relação à Cidade Velha revela o pensamento dos pequenos comerciantes do bairro, que vivem também de renda de aluguel de imóveis no bairro. Nascida no bairro, aos 62 anos de idade, ela percebe que a vida na Cidade Velha mudou devido a falta de liberdade de utilizar a rua como área de lazer e sociabilidade, realizando as festas juninas nas ruas. ${ }^{19}$

Segue a entrevistada narrando as festas de carnaval, de fim de ano realizadas em família, essa familia incluindo naturalmente os vizinhos, considerados como tal. A razão da mudança, segundo ela, é a falta de segurança. Essa condição a faz sentir "tolhida" de realizar sua rotina de trabalho, de frequentar a igreja da Sé aos domingos, de fazer a caminhada na Praça Felipe Patroni. Reclama a falta de um posto policial no bairro, reivindicação já feita "pra uma outra moça que passou fazendo uma pesquisa, parece que para esse departamento de ... Patrimônio Histórico que tem.” As histórias que se seguiram insistiram no moto continuo da falta de segurança.

Porém, aponta como vantagens da Cidade Velha o comércio e os transportes variados, além da proximidade ao mais antigo Shopping da cidade. Não se referiu ao Complexo Feliz Lusitânia, sendo para ela inexistente no seu roteiro de passeios. Percebe-se que para os moradores antigos as igrejas tornam-se importante local de vida social, sendo vistas não como patrimônio histórico ou artístico, mas como locais tradicionais de visitação e reunião, desde a infância. Esta identidade se alia à referência do comércio, a ligação com o Mercado e feira do Ver-o-peso para fazer as compras, que se este estende a todo o bairro da Campina, principal centro comercial de Belém.

\section{MÚLTIPLAS DIMENSÕES DO PATRIMÔNIO NA CIDADE VELHA}

Para os técnicos do projeto "Feliz Lusitânia”, como o historiador Allan Watrin 
Coelho, “... o mote do projeto Feliz Lusitânia é devolver à Cidade Velha, e consequentemente aos monumentos e aos prédios da Cidade Velha, as suas características originais." ${ }^{20}$ Para tal, foram realizadas pesquisas em Arqueologia e História, com a finalidade "de resgatar ao máximo as características arquitetônicas e funcionais do Forte." Como foi impossível trazer o Forte como este foi erigido em 1616, a data mais aproximada encontrada nos vestígios foi a de 1808. Porém, a arquiteta Dorotéa Lima, que participou do processo enquanto técnica do IPHAN, pensa que "aquilo é um Forte do século XX." Critica a ausência de referências explicativas quanto às escolhas adotadas na reforma do Forte do Castelo, tornando obscura a leitura histórica do monumento quanto aos seus vários momentos. ${ }^{21}$

Como pólo de atração ao lazer, o Complexo Feliz Lusitânia vem cumprindo seu papel. As impressões são bastante positivas, destacando-se a paz, a vista da baía e a segurança como qualidades mais apreciadas pelos visitantes. ${ }^{22}$ A maioria dos entrevistados não freqüentava o local antes da restauração, e só após a reforma passou a valorizá-lo como vista para o rio e referencial histórico da cidade de Belém. Os belemenses sentem orgulho de ter um lugar bonito para mostrar aos visitantes de fora.

Maior volume de visitantes se encontra nas partes externas, sendo que muitos jovens que visitaram os museus foram levados pelas escolas. Os que nunca adentraram os Museus alegam como motivos o preço alto dos ingressos para visitar todos os espaços de exposição com a família, ou o desconhecimento sobre o que há de interessante para ser visto.
Uns visitam para "lembrar o passado"; uns reclamam por mais sombra, mais bancos para sentar, telefones públicos, sinalização, coberturas para se abrigar da chuva. Uma visitante chegou a dizer que é preciso ajeitar o muro do forte, pois assim está muito feio, referindo-se à retirada do reboco que recobria as paredes do Forte.

Para a moradora da Cidade Velha "é legal, é melhor do que estava antes, antes o lugar era largado, abandonado, era perigoso, não tinha nem iluminação. Hoje o ponto é um benefício para o bairro, pois vem muito turista, valoriza o comércio imobiliário, entre coisas, é muito bom. Poderia ficar melhor se a direção daí (Complexo) fizesse programações, eventos, para chamar mais pessoas." Embasado na reconquista da "auto-estima dos paraenses", o projeto Feliz Lusitânia vem atraindo um fluxo contínuo de visitantes ao local. No outro extremo do bairro, próximo ao Arsenal de Marinha, foi recentemente inaugurado o Mangal das Garças, Parque Ecológico situado às margens do rio Guamá, e que faz parte dos atrativos turísticos da cidade.

Mas a Cidade Velha não pode ser entendida apenas como patrimônio material, há manifestações significativas que caracterizam o bairro, como as procissões religiosas da Semana Santa, de Santa Maria de Belém e a mais importante, o Círio de Nazaré. Compõem também o mosaico cultural da Cidade Velha os boêmios e os carnavalescos, como o Rubão, proprietário de um pequeno bar para onde se dirigem intelectuais, artistas e jornalistas atraídos pela mística do bairro. Ele se orgulha em dizer que artistas plásticos preferem seu bar ao da Casa das 11 janelas, o "Boteco das 11". 23 No Carnaval, Rubão organiza o Baile da Sereia; o início da festa se 
deve à Sereia como referência das

"[...] famílias portuguesas antigas que moravam aqui na Cidade Velha e era um bar e mercearia. Antigamente a Cidade Velha ela existia muito, em cada esquina dessa aqui era mercearia, era um bar... O baile da Sereia hoje está se tomando assim uma... é pode-se dizer, uma agenda cultural daqui do bairro, aonde as famílias todas descem (...). ${ }^{" 24}$

Rubão é dono do bar que movimenta o pedaço ${ }^{25}$ da Gurupá entre a Cametá e a Rodrigues dos Santos. Organizador do Baile da Sereia, carnaval de rua que homenageia a imagem da Sereia que permanece na fachada do antigo Armazém Sereia, que hoje não funciona mais, ele veste a figura com fantasias de acordo com a época do ano.

O movimento carnavalesco no bairro vem de muito longe. Por volta da década de 40, existiam no bairro núcleos de concentração de blocos carnavalescos, como na casa da Dona Branca, na Gurupá entre Cametá e Rodrigues dos Santos e na casa dos 'Mangabeira', na Cametá. Ainda hoje existem os blocos "Jambú do Kaveira" e "Charanga do Fofó", este organizado pelo cantor Eloy Iglesias, que arrastam pessoas pelas ruas do bairro.

\section{PERCEPÇÕES COMPARADAS}

Também o presente é criado por personagens, cada uma representando um conjunto de falas e pensamentos que convergem para faces diferentes da memória desses lugares, dentre as quais algumas tratam de criá-los como "lugares da memória", na visão de Pierre Nora. A pesquisadora elegeu em Coimbra a Almedina como lócus de inves- tigação, por tratar-se do berço da cidade, e pela presença acentuada de uma população moradora formada por pessoas mais idosas, que nele residem há muitas décadas, e do qual não desejam desapegar-se.

A configuração espacial da Almedina é demarcada pelos muros, objeto que se repete no Complexo Feliz Lusitânia em Belém. Em Almedina, as portas de Barbacã e de Almedina assinalam a entrada em um lugar demarcado física e socialmente, cujo extremo é o cimo da Rua das Covas, que coincide com o Criptopórtico romano. Este realiza a transição temporal das etapas de formação da cidade de Coimbra, bem como é o caminho que leva até a Alta Universitária, com a qual a Almedina mantém fortes relações de dependência.

Em Belém, a relação com o Rio Guamá e a Baia de Guajará, velada em tempos de sua formação colonial nos mil e seiscentos, é também essencial a sua vitalidade, pois através dos barcos chegam e saem mercadorias e pessoas dos interiores ribeirinhos do Pará. Há setores da Cidade Velha que se mantém através da dinâmica com os portos, bem como sua situação contígua ao Centro Comercial mais antigo da Cidade favorece a interação entre eles. Fenômeno similar ao de Almedina, que limita com a Baixa comercial, para onde acorrem seus moradores nas compras diárias e nos passeios.

Assim, a configuração geográfica determina a escolha do sítio da povoação em ambos os casos, sob a ótica da defesa do território, e trás em conseqüência o traçado labiríntico da Alta de Coimbra, bem como a configuração radial de ruas estreitas em Belém, cujo foco é o Forte do Presépio.

Alvo de múltiplos discursos, a Cidade Velha 
é um bairro residencial em fase de declínio, em função do avanço da metrópole em direção a áreas de cota mais alta e que permitiram um novo traçado urbano, mais retilíneo e com espaços mais amplos. Os moradores mais abastados, oriundos de familias "de tradição", aplaudem as reformas, pois as associa com a valorização material e simbólica de seu próprio imóvel como patrimônio, porém os remanescentes de famílias da elite intelectual vêem de maneira crítica as mudanças nos espaços de seu usufruto permanente, assinalando conflitos entre as visões "estética" e "vivencial" dos centros históricos. Para outros segmentos, de famílias decadentes economicamente e de comerciantes, para os quais o bairro é local de sobrevivência, ganham destaque fatores de ordem primária, como a insegurança, mais relevantes que a "consciência histórica". Fazemnos lembrar que, acima da preservação dos Valores, há a necessidade de se garantir os direitos essenciais aos cidadãos. Caso contrário corre-se o risco de que esse bairro perca sua vitalidade natural e que os espaços de preservação sejam totalmente excluídos do mapa mental cotidiano de seus habitantes.

$\mathrm{Na}$ Almedina o foco das intervenções públicas são as habitações, e não os grandes monumentos, as quais, valorizadas em cores contrastantes, tentam encobrir o que se passa com sua população, que carece de atenção a saúde, a segurança, a acessibilidade. O cenário que os governos tentam exaltar, reforçando imagens memoriais, não inclui seus habitantes, que são vistos como estorvos aos planos modernizadores e progressistas.
Françoise Choay (2000) aponta alguns problemas ou efeitos perversos da massificação no processo de preservação de espaços históricos, dentre os quais a transformação dos monumentos em "shopping centers da cultura" e as intervenções a pretexto de preservação do aspecto histórico de certos centros antigos, mas que aplicam estereótipos do lazer urbano, como cafés ao ar livre, tendas de artesanato, galerias de arte, redes de lanchonetes internacionais, restaurantes, desfigurando os aspectos peculiares destes lugares, banalizando-os.

Em Belém, contudo, é inegável que os turistas, bem como os próprios moradores vão aos poucos se integrando ao "Feliz Lusitânia", que se redescobre como vista para o rio, local de passeio, pois que para a população local os espaços externos são muito mais atrativos que os museus. Contemplar as várias imagens que os belemenses formam sobre o núcleo inicial da colonização do Pará: de postal, de praça, de janela para o rio, de museu ao ar livre, de referência para a memória social, é cada vez mais o papel do Forte do Castelo.

Como parte do processo de revitalização, ocorre a absorção de uma população exógena interessada em 'Cultura e Patrimônio', que passa a habitar e/ou utilizar imóveis antigos do bairro com atividades comerciais. Este "enobrecimento", na visão de Zukin (1990), acontece quando um grupo não nativo se apropria da paisagem e do lugar, impondo sua visão transformadora do vernacular em paisagem, conduzindo a um processo de apropriação espacial. Assim, a valorização do cenário antigo leva estes novos grupos a buscar a integração ao lugar, que se dá pela inserção de novos hábitos e modos de vida que mudam o caráter des- 
tas áreas. Esse processo pode ser positivo à medida que revigora e valoriza o bairro, participando de sua tradição, mas incluindo novos usos. A chegada de novos moradores à Cidade Velha, bem como a utilização de espaços como a Praça do Carmo em atividades de lazer e cultura trazem novos ares ao bairro, servindo de incentivadores de mudanças benéficas.

$\mathrm{Na}$ Almedina, os moradores mais antigos temem serem expulsos pela valorização do espaço, da mesma forma que os estudantes das Repúblicas. Para os comerciantes, em especial os que se voltam ao turismo é que as reformas tornam-se oportunidade de negócios. A sede da Universidade é a base das relações que se estabelecem no Centro antigo, em especial na Almedina, que se configura como zona de transição entre a Alta Universitária e a Baixa comercial.

Em relação a candidatura 'Universidade de Coimbra: Património Mundial”, o Centro de Estudos Sociais realizou um levantamento de cunho sociológico da zona tampão de candidatura, que inclui cinco freguesias da cidade: Santa Cruz, São Bartolomeu, Sé Nova, Almedina e Olivais (Fortuna 2006). Dentre os resultados, pode-se perceber a predominância residencial da zona, sendo que quase a metade dos alojamentos coletivos situa-se na Alta, ou seja, as proximidades da Universidade, o que é coerente com o fato de a maioria deles ser destinada ao público estudantil.

A pesquisa atesta que a maioria absoluta dos habitantes nasceu em Portugal, sendo que dos estrangeiros a composição maior é de angolanos, brasileiros e franceses, denotando uma composição homogênea em termos de origem e pelo matiz lusófono. A composição etária da população atinge maior concentração nas faixas entre 16 e 24 anos, ou entre maiores de 65 anos, sendo que a maioria das habitações é arrendada.

Outra conclusão dos estudos é de que as obras realizadas nos últimos 10 anos nos edifícios da zona restringem-se a pequenas melhorias, que não contribuíram para a preservação dessa zona ou para a qualidade de vida de seus moradores. O desejo de permanência na área é justificado pela relação afetiva com a casa, bem como pela vizinhança. Para os jovens, a área é ideal pela centralidade e pela proximidade do local de estudo.

Porém, a visão reabilitadora continua a pensar o espaço como cenário, esvaziado dos problemas humanos, e se esquece que as pessoas é que criam a cidade. Carlos Fortuna fala sobre a autoimagem de Coimbra, que há tempos assimilava a autocomplacência e a idéia da perda, bem como o caráter provinciano, idéias também encontradas em Belém. Permanece o desafio de "como injectar modernidade no Centro histórico da cidade" (Fortuna 2006). Para tal, é preciso que as práticas culturais sejam vivas, que as personagens contribuam para um patrimônio que se reinventa, através da "ancoragem das tradições nas práticas quotidianas.” (Peixoto 2006: 1)

\section{AGRADECIMENTOS}

Pesquisa realizada com o apoio da Bolsa para Jovens Investigadores 2009 do Centro de Estudos Sociais da Universidade de Coimbra, durante o mês de julho de 2009.

\section{NOTAS}

${ }^{1}$ O termo revitalização é utilizado pela equipe técnica que concebeu o Projeto Feliz Lusitâ- 
nia, como parte de um processo de valorização da cultura e do patrimônio como geradores econômicos, em que os altos investimentos em obras são justificados pelo suposto retorno turístico, o que determina um componente político forte nas escolhas e critérios de intervenção, que por vezes não correspondem às diretrizes previstas nas Cartas Patrimoniais. Ver Miranda (2009).

${ }^{2}$ O Projeto Feliz Lusitânia foi iniciado em 1997 e concluído em 2002, sendo coordenado pela Secretaria Executiva de Cultura do Estado do Pará. Abrangeu o núcleo inicial da colonização de Belém, incluindo o Forte do Presépio, Antigo Hospital Militar, Igreja e Colégio de Santo Alexandre, casario da Rua Padre Champagnat e seu entorno.

${ }^{3}$ Entrevista concedida à autora pelo Sr. António Silva em 6 de julho de 2009.

${ }^{4}$ Entrevista concedida a autora pelos estudantes Nuno Lopes, Catarina Fernandes, Ana Costa e Catarina Alves (Tota) no dia 15 de julho de 2009.

${ }^{5}$ Entrevista concedida à autora pela Sra ${ }^{\mathrm{a}}$ Rosa Maria Silveirinha em 6 de julho de 2009.

${ }^{6}$ Entrevista concedida à autora pela $\mathrm{Sr}^{\mathrm{a}}$ Celeste Antunes em 6 de julho de 2009.

${ }^{7}$ Entrevista concedida à autora pela arquiteta Cláudia Ascenso em 8 de julho de 2009.

${ }^{8}$ A Tese "Cidade Velha e Feliz Lusitânia: cenários do patrimônio cultural em Belém" teve por objetivo detectar as percepções da população moradora da área de entorno de bens tombados que fazem parte do Complexo Feliz Lusitânia em relação às mudanças promovidas pelas intervenções do referido projeto.

${ }^{9}$ Estabelecimento de subsistência era um galpão do Exército onde funcionava a Companhia de Abastecimento deste, mas que uma vez por semana era aberto à população para que pudessem lá comprar gêneros alimentícios.

${ }^{10}$ Círculo Militar é o Clube dos Militares do Exército, que tinha a sede social funcionando no
Forte do Castelo, cujo restaurante era aberto à comunidade.

${ }^{11}$ Estação das Docas é o complexo de bares e restaurantes que funcionam em antigos galpões do Porto de Belém que foram reformulados na década de 90 .

${ }^{12}$ Entrevista concedida a autora pela professora $\mathrm{Ma}-$ ria de Belém Menezes em 18 de fevereiro de 2004.

${ }^{13}$ Entrevista concedida a autora pela $\mathrm{Sr}^{\mathrm{a}}$ Oneide Bastos em 20 de fevereiro de 2004.

${ }^{14}$ Fundação Cultural do Município de Belém.

${ }^{15}$ Entrevista concedida à autora por Aprígio Melo Dutra, em 6 de outubro de 2004. Da sacada de sua casa, vê-se todo o Complexo Feliz Lusitânia.

${ }^{16}$ Entrevista concedida a autora pelo arquiteto José Fernandez em 22 de setembro de 2004.

${ }^{17}$ Entrevista concedida à autora por Ana Lúcia Chaves Brahuna, em 23 de setembro de 2004.

${ }^{18}$ O Círio de N. Sr ${ }^{2}$. de Nazaré é o evento religioso mais importante dos paraenses. Realizado não só na capital, como no interior, o Círio ocorre num período de quinze dias do mês de outubro, que começa com a procissão da Trasladação da imagem da Virgem da Capela do Colégio Gentil Bittencourt até a Catedral da Sé, percorrendo os bairros de Nazaré, Comércio e Cidade Velha. Na manhã seguinte à Trasladação, a imagem sai da Catedral percorrendo o mesmo trajeto, em direção à Basilica de Nossa Senhora de Nazaré. Ao lado da Igreja forma-se um arraial com brinquedos e barracas de comidas típicas.

${ }^{19}$ Entrevista concedida à autora pela Sra. Marilza da Conceição Lima Bastos, em 11 de março de 2004.

${ }^{20}$ Entrevista concedida a autora pelo historiador Allan Watrin Coelho, diretor do Museu do Forte do Presépio, em $1^{\circ}$ de abril de 2004.

${ }^{21}$ Entrevista com Dorotéa Lima, Superintendente do IPHAN no Pará, em 13 de agosto de 2009.

22 Aplicação de questionários feita com usuários 
do Complexo nos dias 14 a 21 de março de 2004, em diversos horários, como atividade do Grupo de Pesquisa Cidade, Aldeia e Patrimônio do Laboratório de Antropologia da UFPA. O perfil dos 127 entrevistados abrangeu desde crianças até pessoas com mais de 60 anos, sendo que a maioria dos entrevistados possui entre 21 e 35 anos, é morador dos bairros da $1^{a}$ légua patrimonial de Belém.

${ }^{23}$ A Casa das 11 janelas foi Hospital Militare Quartel do Exército até a restauração da área denominada "Feliz Lusitânia" pelo Governo do Estado do Pará.

${ }^{24}$ Entrevista concedida a autora por Rubem Estevam Lobato, em 11 de fevereiro de 2004.

25 Magnani esclarece o sentido de "pedaço" como uma "intricada rede de relações formada por laços de parentesco, vizinhança e coleguismo."(Magnani 1998:113) São dois os elementos constituintes do "pedaço": um componente espacial a que corresponde uma determinada rede de relações sociais. Alguns pontos de referência delimitam seu núcleo: o telefone público, a padaria, alguns bares e comércios, $\mathrm{o}$ terreiro e o templo, o campo de futebol e algum salão de baile. Não basta, contudo, morar perto do pedaço para pertencer a ele - é preciso estar situado numa rede de relações que combina parentesco, vizinhança e procedência.

\section{REFERÊNCIAS}

Augè, M. 2001. Não-lugares: introducão a uma antropologia da supermodernidade. (Coleção Travessia do Século)Campinas: Papirus.

Benjamin, W. 1985. A obra de arte na era de sua Reprodutibilidade técnica, in Obras Escolbidas v. 1. Tradução de José Carlos Martins Barbosa. São Paulo: Brasiliense.

Choay, F. 2000. A alegoria do patrimônio. Lisboa: Edições 70.

Coimbra. Câmara Municipal. 2005. Relatório Interdisciplinar da Baixa. Disponível em: http://www.coimbravivasru.pt/pdf/ relatorio_marco_2005.pdf. Acesso em 18 out 2008.
Coimbra. Câmara Municipal. 2006. Candidatura ao Programa de Recuperação de Áreas Urbanas Degradadas. Coimbra: Gabinete para o Centro Histórico.

Fortuna, C. 1997. Destradicionalização e imagem da cidade, in Cidade, cultura e globalização - Ensaios de sociologia. Organizado por C. Fortuna, pp. 231-257. Lisboa: Celta Editora.

Fortuna, C.; C. Ferreira; P. Abreu; P. Peixoto e C. Gomes. 2006. A Alta da Cidade de Coimbra. processos de revalorização patrimonial e dinâmicas de recomposição sócio-cultural. Coimbra: CES. Relatório Final de Pesquisa.

Frias, A. \& P. Peixoto. 2000. Representação imaginária da cidade. Processos de racionalização e de estetização do patrimônio urbano de Coimbra. Oficinas do CES No 183.

Magnani, J. G. C. 1998. Festa no pedaco: cultura popular e lazer na cidade. São Paulo: Hucitec; UNESP.

Melo, M. 2009. Coimbra. Viageme Twirsmo 10: 73-74.

Miranda, C. S. 2009. Cultura e Patrimônio em BelémPA: uma história de profissionalização. 80 p. Monografia $\left(1^{\circ}\right.$ Edital de Seleção de Pesquisas A Preservação do Patrimônio Cultural no Brasil) Instituto do Patrimônio Histórico e Artístico Nacional. Brasil, Belém.

Nora, P. 1997. Les L ienx de Mémoire. Paris: Gallimard.

Peixoto, P. 2006. O Passado ainda não comegou: funcões e estatutos dos centros históricos no contex to urbano português. Tese de Doutorado. Faculdade de Economia, Universidade de Coimbra, Coimbra.

Tocantins, L. 1976. Santa Maria de Belém do Grão Pará. instantes e evocações da cidade. Rio: Civilização Brasileira; Brasilia: INL.

Zukin, S. 1996. Paisagens urbanas pós-modernas: mapeando cultura e poder. Revista do Patrimonio Histórico e Artístion Nacional 24: 205-219.

Recebido em 10/04/2011.

Aprovado em 02/09/2011. 